\title{
Menadionun Dayanılılı̆̆ı (Stabilitesi) Üzerinde Bir Araştırma
}

\author{
A Research on the Stability of Menadione \\ Muzaffer TUNÇEL
}

\section{ÖZET}

Sabit iyon şiddetinde $(\mathrm{I}=0.5)$ yapılan kinetik deneylerde, çeşitli pH ve sicaklıklardaki menadion çözeltilerinin reaksiyon hız değişmezleri saptanmıştır. Bu hız değişmezleri kullanılarak molekülün aktivasyon enerjisi $17.6 \mathrm{~K}$ cal/mol olarak hesaplanmıştır. Reaksiyon hız değişmezlerinin pH'a göre incelenmesinde, menadionun baz katalizli parçalanmasının pH 9'un üzerinde oldukça hızlı olduğu sonucuna varılmıştır.

\section{SUMMARY}

The reaction rate constants of menadion solutions of various $\mathrm{pH}$ and temperatures were determined in the kinetic experiments carried out at constant ionic strength $(I=0.5)$. By using these rate constants, the activation energy of molecule was calculated as 17.6 $\mathrm{K}$ cal/mol. According to the changes of the reaction rate constants with $\mathrm{pH}$, it was concluded that the base-catalysed degradation of molecule was rather fast above pH 9.

Anahtar Kelimeler: Menadion, kimyasal kinetik

İlaç endüstrisi ve araştırma laboratuvarları elli yıldan beri dayanıklılık testleri üzerinde önemle durmaktadır. Bilindiği gibi dayanıklı-

Redaksiyona verildiği tarih: 5 Mart 1984

Analitik Kimya Anabilim Dalı, Eczacılık Fakültesi, Ankara Üniversitesi 
lık çalışmaları fizikokimyasal temellere dayanmaktadır ve bu dala fizikokimyada kimyasal kinetik denilmektedir. Bu konuda önceleri ampirik kavramlardan yararlanılarak çalışmalar yapılmış, bu kavramlar zamanla geliştirilmiş ve bilimsel temellere oturtulmuştur. Günümüzde yapılan dayanıklılık deneyleri ile ilaçların bozunmaları konusunda birçok parametre tayin edilebilmekte ve parametreler arasındaki ilişkiler incelenebilmektedir (1-3).

Kimyasal kinetiğin hızla gelişmesi, ilaçların organizmadaki dayanıklılıklarının incelenmelerine olanak sağlamıştır. Böylece ilaçların organizmadaki absorbsiyon, dağılım, biyoyararlılık ve atılımının kantitatif olarak değerlendirilmesi, kimyasal kinetiğe dayalı olarak yaprlabilmektedir $(4,5)$.

$\mathrm{K}_{3}$ vitamini olarak bilinen manadionun, organizmada kanın pıhtılaşmasına neden olan etkisinin yanı sıra, oksidatif fosforilasyonda da görev aldığı ileri sürülmektedir (6). Menadionun çözeltileri 1şıkta bozulmakta ve çeşitli kimyasal reaksiyonlar sonucu iki elektron alarak hidrokinonik yapıya dönebilmektedir. Bu araştırmada, kolayca reaksiyona girebilen bir yapıya sahip olan menadionun dayanıklılı koşulları; değişmez iyon şiddetinde, sıcaklığa ve pH'a bağlı olarak incelenmiştir.

\section{MATERYAL VE METOD}

Menadionun reaksiyon hızı değişmezleri çeşitli pH tamponları içerisinde ve sıcaklıklarda, kimyasal kinetik çerçevesinde incelenirken aşă̆ıdaki çalışma yolu izlenmiştir.

Menadion bazik ortamda dayanıklı olmadı̆̆ 1 için bazik bir tampon olan $\mathrm{NaHCO}_{3}-\mathrm{NaOH}$ tamponundan yararlanilarak dört değişik pH'a sahip reaksiyon çözeltileri hazırlanmıştır (7). Bu çözeltilerin hazırlanmasında kullanılan kimyasal maddeler, bunların molar derişimleri ve çözeltilerin iyon şiddetlerini $\mathrm{I}=0.5 \mathrm{de}$ değişmez tutmak için katılması gerekli NaCl'ün molar derişimleri Tablo I'de verilmiştir.

Reaksiyon çözeltileri, Tablo I'de molar değerleri verilen kimyasal maddelerin $100 \mathrm{ml}$ için gerekli miktarlarının $85 \mathrm{ml}$ suda çözülmesi ve etanol ile $100 \mathrm{ml}$ ye tamamlanmaları ile elde edilmektedir. Böy- 
Tablo I: Reaksiyon çözeltilerinin hazırlanmalarında kullanılan kimyasal maddelerin molar derişimleri

\begin{tabular}{|lrl|c|c|c|}
\hline & & {$\left[\mathrm{NaHCO}^{3}\right]$} & {$[\mathrm{NaOH}]$} & {$[\mathrm{NaCl}]$} \\
\hline Çözelti & I & (Ç-I) & 0.025 & 0.0227 & 0.4523 \\
Çözelti & II & (Ç-II) & 0.025 & 0.0191 & 0.4559 \\
Çözelti & III & (Ç-III) & 0.025 & 0.0170 & 0.4580 \\
Çözelti & IV & (Ç-IV) & 0.025 & 0.0050 & 0.4700 \\
\hline
\end{tabular}

lece belli pH ve değişmez iyon şiddetinde çözeltiler hazırlanmış olmaktadir. Burada kullanılan etanolun görevi menadionun çözücüsü olmasidir.

pH, sıcaklığın bir işlevi olarak değiştiğinden, hazırlanan reaksiyon çözeltilerinin çalışma sıcaklığındaki gerçek pH değerlerinin ölçülebilmesi için ölçüm yapılan pH metre, sıcaklık ile pH değerleri değişen $0.025 \mathrm{M} \mathrm{K} \mathrm{H}_{2} \mathrm{P}_{4}-0.025 \mathrm{M} \mathrm{N} \mathrm{a}_{2} \mathrm{H} \mathrm{PO}_{4}$ standart tamponu (8) ile çalışma sıcaklığında sahip olduğu pH'a ayarlanmıştır. Hazırlanan reaksiyon çözeltilerinin pH değerleri reaksiyonların yürütüldüğü sıcaklıklarda ayrı ayrı ölçülmüştür. pH ölçümlerinde Tacussel (TS $70 \mathrm{~N}-1)$ pH metre kullanılmıştır.

Reaksiyonun yapıldı̆̆ 1 yă banyosu deney başlamadan en az bir saat önce çalıştırılmıştır. Böylece reaksiyon çözeltileri için homojen bir sıcaklık sağlanmıştır. Bu amaç için Heidolff marka termostatlı yă̆ banyosu kullanılmıştır.

Balonjojeler içerisindeki reaksiyon çözeltileri yaklaşık iki saat reaksiyonun yapılacağı yă̆ banyosunda dengelenmiş, sonra belli derişimlerdeki menadionun etanoldeki çözeltisinden katılarak reaksiyon başlatılmıştır.

Kiyasal kinetik deneylerinde numune alma zamanları büyük önem taşımaktadır. Çeşitli sıcaklıklarda yapılan kaba deneylerle bulunan reaksiyon hızı değişmezleri değerlerinden hareketle, başlangıç derişiminin yüzde 90, 80, 70, 60, 50 ve 40 1na karşı gelecek yaklaşık numune alma zamanları hesaplanmış ve bu sürelerde numune alınarak değerlendirmeye katılan noktaların geçerliliği sağlanmıştır.

Sönümleme işlemi $10 \mathrm{ml} 0.05 \mathrm{M} \mathrm{HC1}$ bulunan tüpler içerisinde yapılmıştır. Yaklaşık numune alma sürelerine karşı gelen zamanlarda 
$2.0 \mathrm{ml}$ numune reaksiyon balonjojesinden pipetle alınmış ve buzla soğutulmuş tüpler içerisine katılarak reaksiyon durdurulmuştur. Bu süreçte reaksiyon süreleri kaydedilmiştir.

Bir reaksiyonun tüm numune alma işlemleri sona erdikten sonra alınan numuneler, menadionun en yüksek soğurma verdiği $249 \mathrm{~nm}$ de Beckman DG-BT ultraviole spektrofotometresinde ölçülmüş ve elde edilen sonuçlar reaksiyon hız değiş̧mezlerinin hesaplanmasında kullanılmıştır.

\section{SONUÇ ve TARTIŞMA}

Reaksiyon çözeltilerinin pH'ları çalışma sıcaklıklarında ölçülmüştür. Hazırlanan çözeltilere verilen simgeler ve çalışma sıcaklıklarında ölçülen pH değerleri Tablo II'de verilmektedir.

Tablo II: Hazırlanan reaksiyon çözeltilerinin çeşitli sıcaklıklardaki pH'ları

\begin{tabular}{|c|r|r|r|}
\hline \multirow{2}{*}{} & \multicolumn{3}{|c|}{ P H değerleri } \\
\cline { 2 - 4 } & $70^{\circ} \mathrm{C}$ & $60^{\circ} \mathrm{C}$ & $50^{\circ} \mathrm{C}$ \\
\hline Ç - I & 10.33 & 10.30 & 10.28 \\
Ç - I I & 10.20 & 10.16 & 10.12 \\
Ç - I I I & 9.89 & 9.85 & 9.82 \\
Ç - I V & 9.42 & 9.37 & 9.28 \\
\hline
\end{tabular}

Reaksiyon sürecinde alınan numunelerin soğurma değerleri ultraviole spektrofotometresinde okunmuş, zamana karşı $A_{t}-A_{\infty}$ değerleri Şekil la ve lb de grafiğe alınmışlardır.

A $\infty$, menadionun tümüyle bozunmasından sonra gösterdiği absorbans olup, At - $A_{\infty}$ değerleri menadionun karşı geldiği süredeki derişimini vermektedir. Zamana karşı $1 \mathrm{n}$ (At-A $\infty$ ) değerlerinin Şekil $2 a$ ve 2 b'de olduğu gibi doğrusal değişim göstermesi nedeniyle menadionun baz katalizli parçalanma reaksiyonunun birinci derece olduğu saptanmıştır (3).

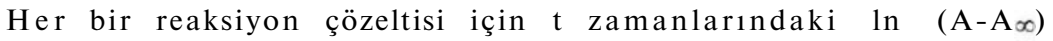
değerlerinin regresyon analizleri yapılmış, doğruların eğim ve kesimleri bulunmuştur. Bulunan eğim değerleri reaksiyon hız değişmezine, 
Menadionum Dayanıklılı̆̆

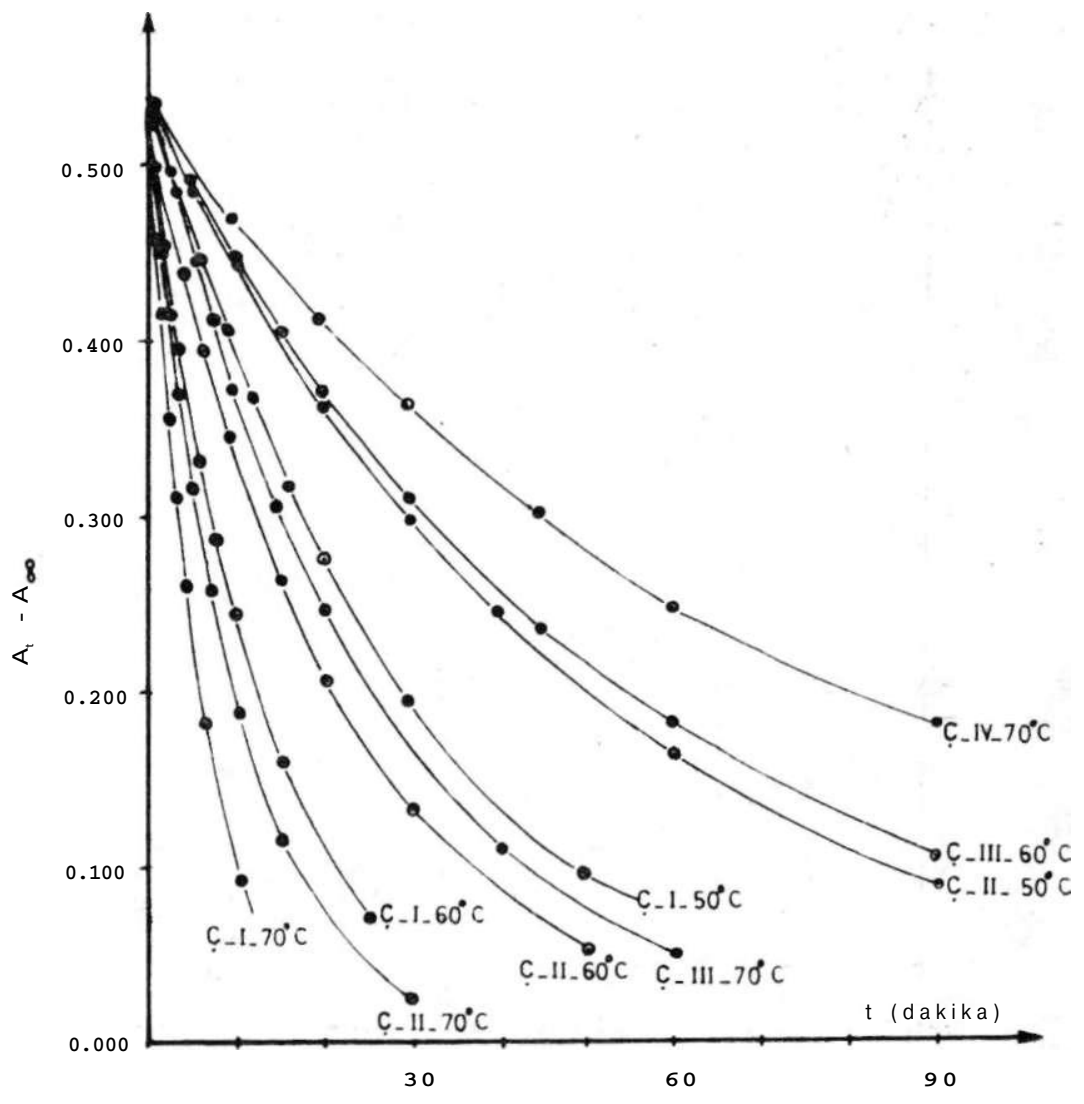

Şekil 1a: Menadionun bozanına eğrileri.

kesim değerleri ise menadionun başlangıç derişimine karşı gelmek tedir. Bu değerler Tablo III'de toplanmıştır.

Reaksiyon hız değişmezlerinin aktivasyon enerjisi ve frekans fak törü ile ilgisi Arhenius denklemi adı ile bilinen,

$\mathrm{k}=\mathrm{S} \mathrm{e}^{-\mathrm{Ha} /{ }^{\mathrm{RT}}}$ denklemi ile verilir.

Buradak : hız değişmezini,

$\mathrm{H}_{\mathrm{a}}$ : aktivasyon enerjisinini,

S : frekans faktörünü, 


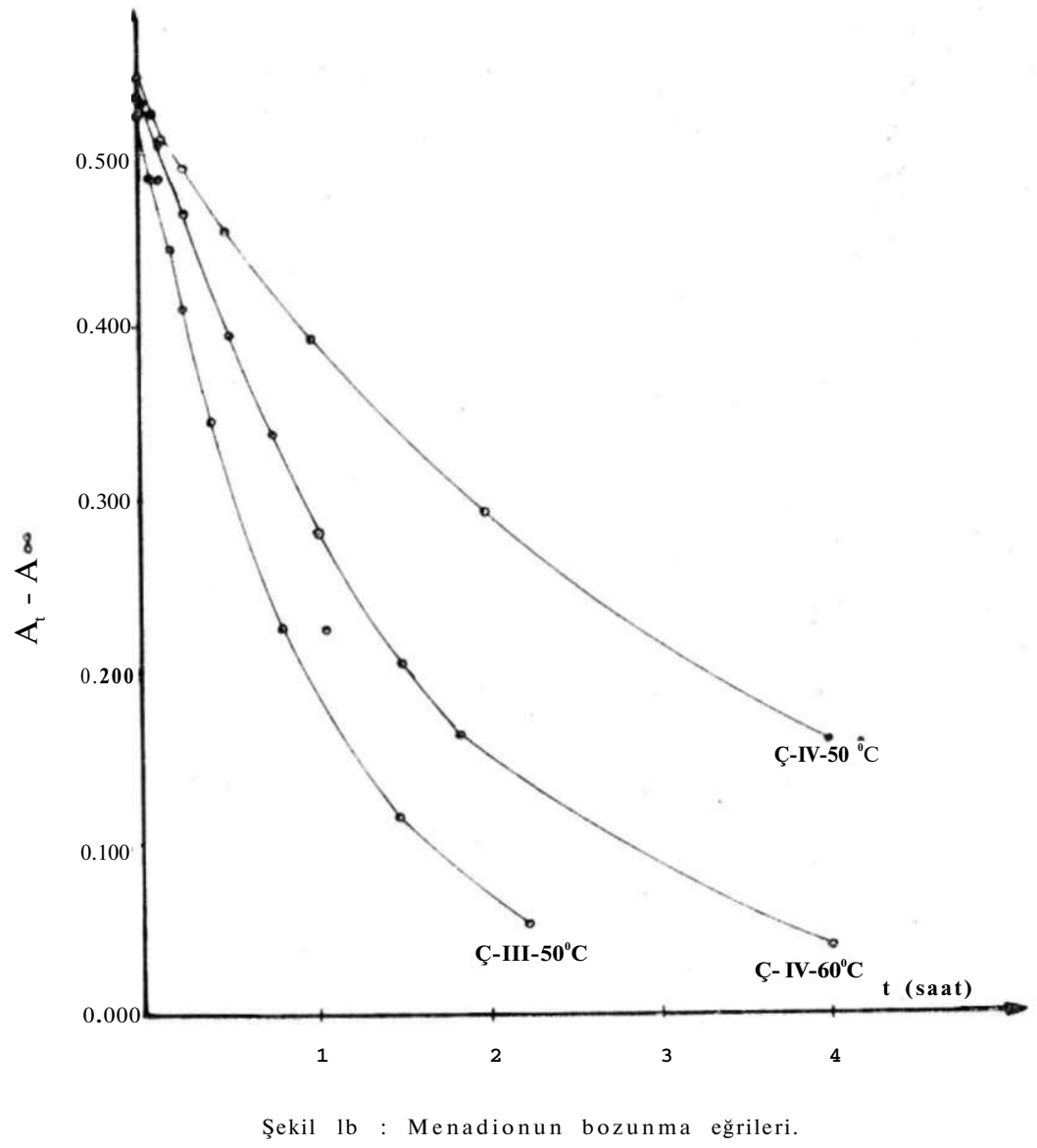

R : gaz sabitini,

$\mathrm{T}$ : mutlak sicaklığı simgelemektedir.

Denklem :

$1 \mathrm{n} \mathrm{k}=\mathrm{H}_{\mathrm{a}} / \mathrm{RT}+\ln \mathrm{S}$ şeklinde yazıldı̆̆ında $1 / \mathrm{T}-1 \mathrm{n} \mathrm{k}$ grafiğinde eğimin $H_{a} / R$ ifadesine eşit olacağı ortadadır.

Aktivasyon enerjisinin hesaplanabilmesi için çeşitli sıcaklıklardaki reaksiyon hız sabitleri Tablo IV'de toplanmıștır. 
Tablo III: Reaksiyon sonunda hesaplanan reaksiyon hız değişmezleri ve menadion başlangıç derişimleri

\begin{tabular}{|c|c|c|}
\hline & $\mathrm{A}$, & $\mathrm{k}\left(\mathrm{dakika}^{-1}\right)$ \\
\hline $\mathrm{C}-\mathrm{I}-70^{\circ} \mathrm{C}$ & 0.524 & 0.1689 \\
\hline $\mathrm{C}-\mathrm{II}-70^{\circ} \mathrm{C}$ & 0.535 & 0.1054 \\
\hline Ç-III- $70^{\circ} \mathrm{C}$ & 0.549 & 0.0399 \\
\hline $\mathrm{C}-\mathrm{IV}-70^{\circ} \mathrm{C}$ & 0.530 & 0.0124 \\
\hline $\mathrm{C}-\mathrm{I}-60^{\circ} \mathrm{C}$ & 0.536 & 0.0803 \\
\hline $\mathrm{C}-\mathrm{II}-60^{\circ} \mathrm{C}$ & 0.530 & 0.0463 \\
\hline Ç - III - $60^{\circ} \mathrm{C}$ & 0.530 & 0.0181 \\
\hline Ç- IV $-60^{\circ} \mathrm{C}$ & 0.550 & 0.0055 \\
\hline $\mathrm{C}-\mathrm{I}-50^{\circ} \mathrm{C}$ & 0.557 & 0.0351 \\
\hline $\mathrm{C}-\mathrm{II}-50^{\circ} \mathrm{G}$ & 0.539 & 0.0199 \\
\hline Ç-III- $50^{\circ} \mathrm{C}$ & 0.525 & 0.0085 \\
\hline Ç-IV-50 $\quad{ }^{\circ} \mathrm{C}$ & 0.530 & 0.0025 \\
\hline
\end{tabular}

Tablo IV: 1/T ve reaksiyon hız değişmezleri

\begin{tabular}{|l|c|c|c|c|l|}
\hline \multicolumn{2}{|c|}{ Sicaklık } & \multicolumn{4}{|c|}{$\mathrm{k}$} \\
\hline $\mathrm{t}^{\circ} \mathrm{C}$ & $\mathrm{I} / \mathrm{T}\left({ }^{\circ} \mathrm{K}^{-1}\right)$ & Ç-I & Ç- II & Ç- III & Ç-IV \\
70 & 0.00291 & 0.1689 & 0.1054 & 0.0399 & 0.0124 \\
60 & 0.00300 & 0.0803 & 0.0464 & 0.0181 & 0.0055 \\
50 & 0.00309 & 0.0351 & 0.0199 & 0.0085 & 0.0025 \\
\hline
\end{tabular}

Tablo IV'deki $1 / \mathrm{T}$ ve $\mathrm{k}$ değerlerinin doğal logaritmik değerleri kullanılarak Arhenius eğrileri Şekil 3'de grafiğe alınmışlardır. Bu değerlerin regresyon analizleri yapılmış ve aşağıdaki denklemler bulunmuştur.

$$
\begin{aligned}
& \text { Ç-I } \quad \mathrm{y}=[23.63 \pm(12.71)(0.8158)]-[8728 \pm(12.71)(271.85)] \mathrm{x} \\
& \text { Ç-1I } y=[24.70 \pm(12.71)(0.2472)]-[9261 \pm(12.71)(82.39)] x
\end{aligned}
$$

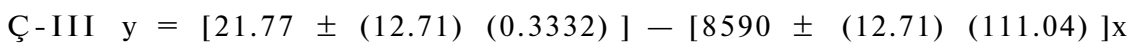

$$
\begin{aligned}
& \text { Ç-IV y }=[21.49 \pm(12.71)(0.0537)]-[8896 \pm(12.71)(17.91)] \mathrm{x}
\end{aligned}
$$

$\mathrm{Bu}$ denklemlerin eğimlerinin ortalaması $8869 \pm 289.9$ tur.

Eğim değerlerinden hareketle; $H_{a}=$ eğim $x$ eşitliğinden aktivasyon enerjisi $17.6+0.6 \mathrm{~K}$ cal/mol bulunmuştur.

Reaksiyon hız değişmezlerinin pH ile değişimini incelemek amacı ile, Tablo II'deki pH ve Tablo III'deki k değerleri kullanılarak Şekil 4'deki eğriler elde edilmiştir. 


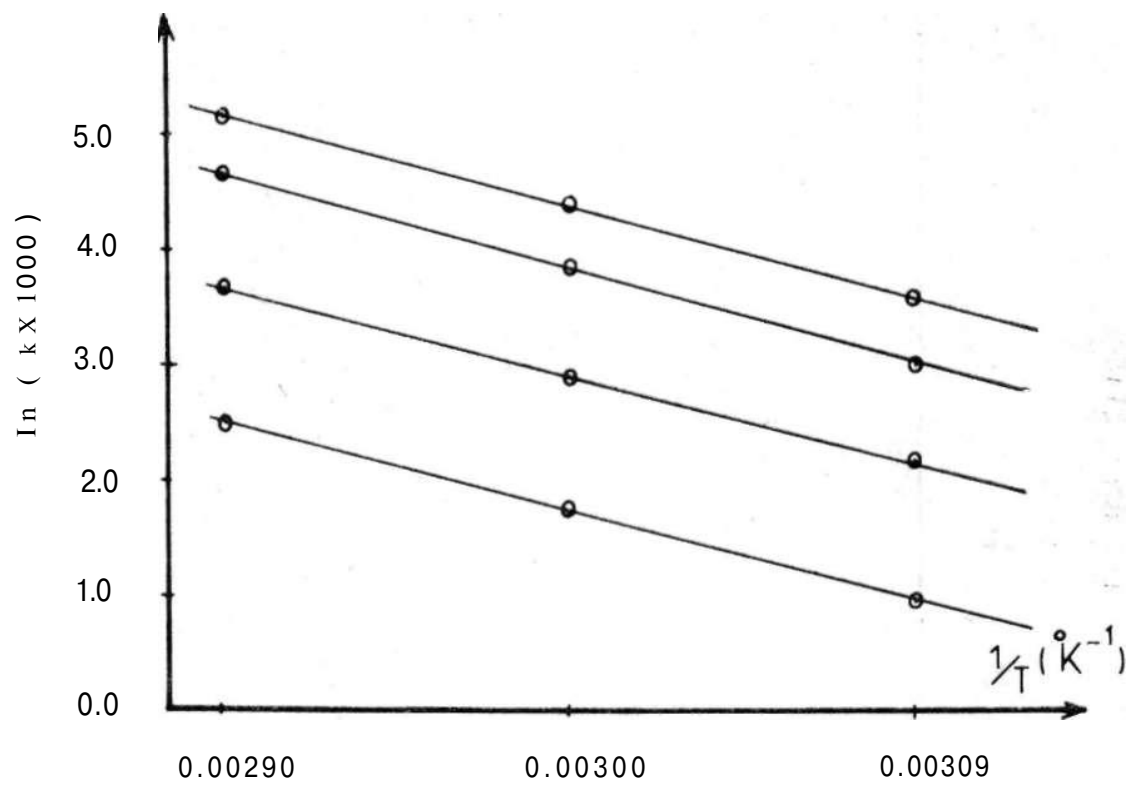

Şekil 3 : Menadionun Arhenius eğrileri

Sıcaklığın pH üzerine önemli ölçüde etkidiği göz önüne alınarak hazırlanan reaksiyon çözeltilerinin pH ları, pH sı sıcaklık ile değişen standart tampona göre ayarlandıktan sonra ölçüm yapılarak tayinlerin duyarlılı̆̆

Menadionun dayanıklığı konusunda yapılmış fazla çalışma olmadığı için değerlerin karşılaştırılması olanağı olmamıştır. DAABİS ve SALEH (9) tarafindan hidrotropik tuzlarının menadionun stabilitesi üzerine etkisini incelemek amacı ile yapılan bir çalışmada menadionun bozunma kinetiği araştırılmış ve bizim bulgularımızda olduğu gibi reaksiyonun birinci derece olduğu bulunmuştur. Bu araştırmada iyon şiddeti ile ilgili herhangi bir kayda rastlanmamıştır. Ayrica $5 \mathrm{mg}$ menadionun $40 \mathrm{ml}$ borat tamponunda 1sıtılarak çözüldüğü, çözülen menadionun soğutulduktan sonra çeşitli sıcaklıklarda reaksiyona sokulduğu, çalışma sıcaklığına kadar ulaşıldıktan sonra bu çözeltiden numune alınmaya başlandı̆̆ı belirtilmektedir. Bu isıtma işlemi ve reaksiyon çözeltisinin yă banyosunda dengeye getirilmeden reaksiyonun başlatılması konulan tartışılabilir. 


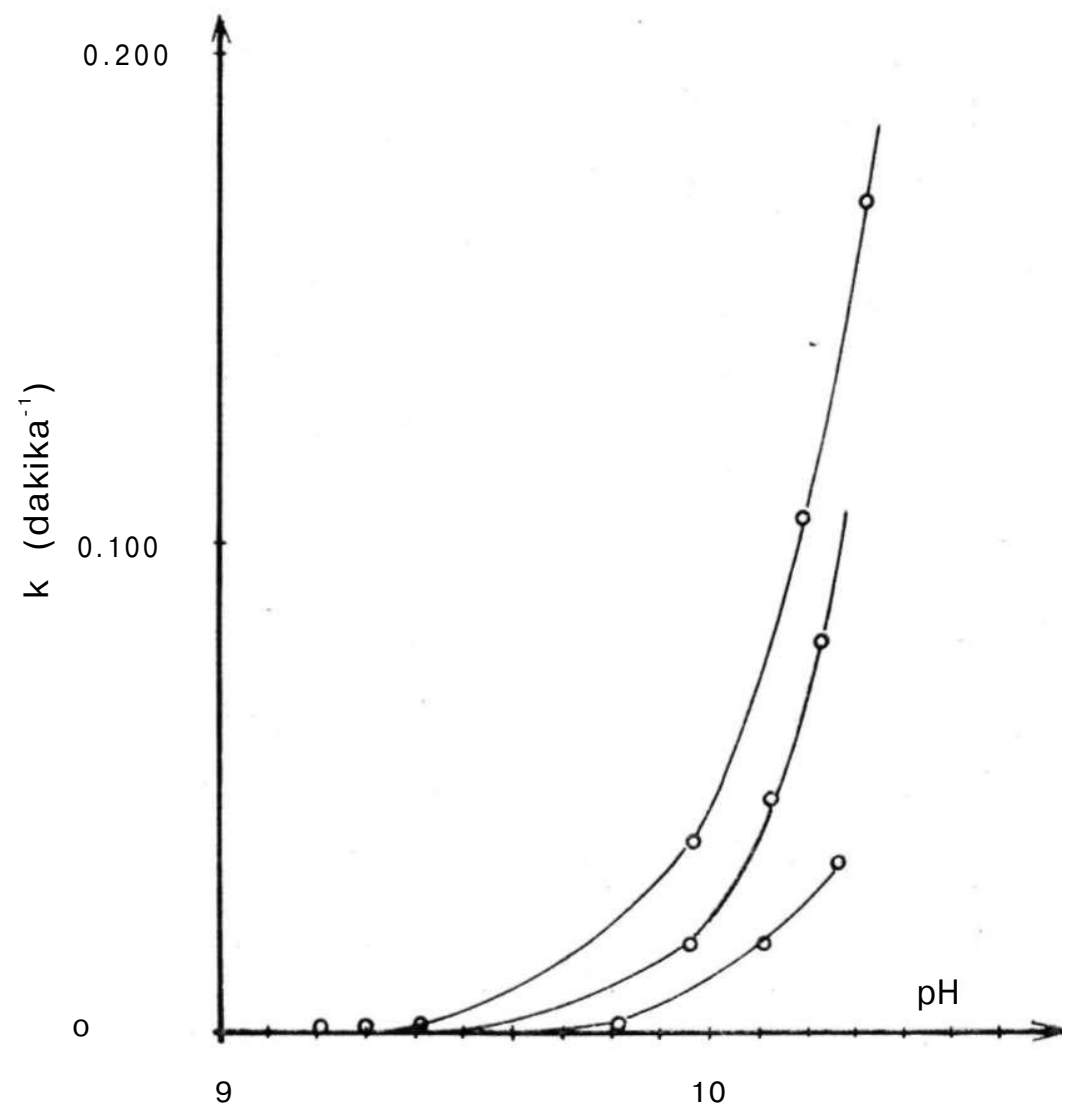

Şekil 4 : Menadionun hız değişmezlerinin pH ile değişim grafiği.

Aynı çalışmada aktivasyon enerjisi hidrotropik tuzlar beraberliğinde ve yalnız menadion için belirlenmiş, $20.7 \mathrm{~K}$ cal/mol bulunmuştur. Bu araştırmada bulunan değer $17.6 \mathrm{~K}$ cal/mol dür. Aktivasyon enerjileri arasındaki farkın, pH'ın sıcaklıkla değişimi dikkate alınmadığından ileri geldiği sanılmaktadır.

Şekil 4'de bozunma hız değişmezlerinin pH ile değişiminde; $70{ }^{\circ} \mathrm{C}$ de $9.7,60{ }^{\circ} \mathrm{C}$ de pH, $50{ }^{\circ} \mathrm{C}$ de 10.2 de çok arttı̆̆ 1 görülmektedir. Bütün bu bulgular pH 9'un üzerinde menadionun dikkate değer bir hizla bozunduğunu göstermektedir. 


\section{LİTERAT ÜR}

1- Frost, A. A., Pearson, R. G.: Kinetics and Mechanism, Second Ed., John Wiley and Sons Co., New York (1961)

2- Glasston, S., Laidler, K. J., Eyring, H.: The Theory of Rate Processes, Mc Graw-Hill Co., New York (1941)

3- Panchenkov, G. M., Lebedev, V. P.: Chemical Kinetics and Catalysis, Mir Publishers, Moscow (1976)

4- Notari, R. E.: Biopharmaceutics and Clinical Pharmacokinetics, Third Ed., Marcel Dekker Inc., New York (1979)

5- Wagner, J. G.: Fundamentals of Clinical Pharmacokinetics, Drug Inleligence Publication Inc., Illinois (1979)

6- Redfearn, E. R.: Mode of Action of Ubiquinones (Coenzymes $Q \_$) in Electron Transport System, Vitamins and Hormons., 24, 465 (1966)

7- Bates, R. G., Bowers, V. E.,: Alkaline Solution for pH control. Anal. Chem., 28, 1322 (1956)

8- Bates, R. G., Bowers, V. E.: The Measurement ofpH. "Handbook of Analytical Chemistry" de Ed. L. Meites. Bölüm 11. Mc Graw-Hill Book Co. New York (1963)

9- Daabis, N. A., Saleh, A. M.: Effect of Hydrotopic Salts on the Stability of Menadion. Canadian J. of Pharm. Sci., 9, 24 (1974) 